\title{
Dealing with an Overdose of Photovoltaics at Distribution Level
}

\author{
Yves Vencken, Wouter Labeeuw and Geert Deconinck \\ Department of Electrical Engineering \\ ESAT/ELECTA, KU Leuven \\ Kasteelpark Arenberg 10, bus 2445 \\ B-3001 Leuven, Belgium \\ \{yves.vencken, wouter.labeeuw, geert.deconinck\}@esat.kuleuven.be
}

\begin{abstract}
Injection of large amounts of active power in the highly resistive distribution network by photovoltaic installations causes the voltage to rise along the feeder. This voltage rise is one of the major challenges the distribution network operator has to face. Rising voltage causes generators to trip with a loss of green energy at the most productive moments as a consequence. A technique known as Active Power Curtailment (APC), proposed by Tonkoski et al., is implemented on a part of a typical European distribution grid. The resulting energy yields are compared to the situation in which the inverter switches off. APC results in a serious decrease of production. Therefore, a modified version of APC, called APC-PI is proposed. By transforming APC from a proportional feedback controller to a PI controller, the total energy yield can be increased by as much as $40 \%$ in comparison to the production of APC controlled generators.
\end{abstract}

Index Terms-electric variables control, distributed power generation, photovoltaic systems, voltage control

\section{INTRODUCTION}

Due to growing concerns about global warning, increasing energy costs and governmental subsidies the number of photovoltaic (PV) installations in residential areas in Belgium has more than hundredfold [1]. The Flemish government rewards the producers of green energy with a green certificate. The number of those certificates paid out has increased from 1356 in 2006 to 459518 in 2010 [2]. The success of PV installations as a family investment and the resulting large-scale implementation of distributed generation (DG) contrasts with the small amount of regulatory measures for the connection of those installations. This has led to a situation where the distribution system operator (DSO) has lost an accurate overview of the number, location and amount of DG [3]. This results in a lot of challenges for the DSO like reverse power flows and stability problems. The voltage rise problem is another of those challenges. Besides possible damage to critical loads, also the loss of green energy at the most productive moments due to the PV inverters switching off is a very important problem [2]. This paper focuses on this last issue.

The implementation of a smart grid deals with a lot of the DSO's challenges. Advanced metering infrastructure is at the core of all smart grid definitions. It refers to smart meters and the accompanying communications network for two-way communication between the provider and the meter [4]. The operation of a smart grid is not simple because it consists of multiple interdependent abstraction layers. Communication problems or failure of the central data processing unit must be overruled by systems on a lower level of abstraction. This paper looks at the problem of overvoltage on a low abstraction level and therefore omits smart grid technologies.

\section{Problem Definition}

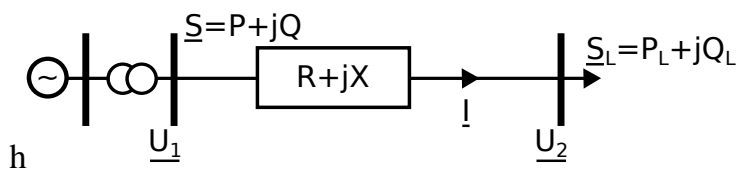

(a) Scheme

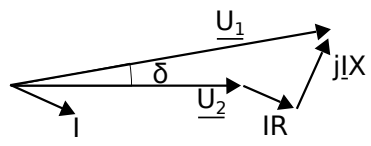

(b) Phasor Diagram

Fig. 1: Scheme (a) and corresponding phasor diagram (b) of the voltage drop over a feeder

The situation in figure 1 is written as [5]:

$$
\begin{array}{r}
U_{2} \sin \delta=\frac{X P-R Q}{U_{1}} \\
U_{1}-U_{2} \cos \delta=\frac{R P+X Q}{U_{1}}
\end{array}
$$

On high voltage lines, $\mathrm{R}$ is often neglected because $X>>R$. Due to the more resistive character of distribution grids this simplification is invalid. If the power angle $\delta$ is small, then $\sin \delta=\delta$ and $\cos \delta=1$. Equations 1 and 2 become:

$$
\begin{array}{r}
\delta \approx \frac{X P-R Q}{U_{1} U_{2}} \\
U_{1}-U_{2} \approx \frac{R P+X Q}{U_{1}}
\end{array}
$$

The active power through the line causes the voltage difference across the line to rise. Because the power flows from bus 1 to bus 2 this means a load is present at the second bus 
and therefore $U_{2}$ is lower than $U_{1}$. When a PV installation located at bus 2 injects active power in the line, the voltage at bus 2 rises above the the voltage at the first bus which illustrates the problem of overvoltage in case of decentralized production. Therefore, reducing the injection of active power mitigates voltage rise; a technique known as Active Power Curtailment (APC) [6]. Overvoltage can also be mitigated by changing the tap of a transformer under load, reactive power control and local energy buffering [2].

\section{Distribution Network Modeling}

For this paper a distribution network is modeled in Matlab $^{\text {TM }}$ and Simulink ${ }^{\mathrm{TM}}$. In order to get realistic grid behavior the model uses different types of customers. Their load profile, being synthetic, is generated by a residential electrical load generator described in [7]. The size of their photovoltaic installations is determined by a rule of thumb that states that one should install enough solar panels to cover the own electrical energy consumption. The yearly yield of PV installations in Belgium is considered to be about $850 \mathrm{kWh} / \mathrm{kWp}$ [2], [3]. A simple single-diode model with neglected shunt resistor [8], [9], [10], [11] receives temperature and irradiance of a typical summer day in Leuven from the Photovoltaic Geographic Information System of the Joint Research Centre of the European Commission [12] as inputs. This ensures a realistic production profile. The grid consist of a $630 \mathrm{kVA}$ transformer with the tap set to $240 \mathrm{~V}$ and two independent EAXVB 4x95 $\mathrm{mm}^{2}$ feeders, each delivering power to 30 customers [13], [14]. The European distribution grid is characterized by the distribution of the three phases and the neutral conductor. Each customer is connected between one of the phases and the neutral conductor. To simulate a symmetrical load, the consecutive houses are connected between different phases. Phase $U$ feeds customer 1 , the second customer is connected on phase $\mathrm{V}$ while customer 3 is fed by phase $\mathrm{W}$. The distance between the houses is $25 \mathrm{~m}$. The Belgian Synergrid C10/11 standard, which is derived from the European standard EN50160, specifies that $95 \%$ of the 10 minute average RMS voltage at medium and low voltage level must be within $\pm 10 \%$ of the nominal voltage [2], [15].

\section{Droop Based Active Power Curtailment}

Tonkoski et al. [6] present a droop based active power curtailment technique for overvoltage prevention on the American split-phase grid. Usually grid-tie inverters are controlled as current sources with maximum power point tracking (MPPT) algorithms. Tonkoski et al. propose that the power injected by the inverter is a function of the bus voltage $U$ according to:

$$
P_{i n v}=P_{m p p t}-m\left(U-U_{c r i}\right)
$$

In this equation $P_{m p p t}$ is the maximum power available in the PV array for a given solar irradiance, $\mathrm{m}$ is a slope factor [W/V] and $U_{c r i}$ is the voltage above which the power injected by the inverter is decreased with a droop factor. For $U<U_{c r i}$ the inverter injects $P_{m p p t}$. This method uses local voltage to define how much power should be curtailed from each PV inverter. The slope factor is defined as in Equation 6 .

$$
m=\frac{P_{p v \max }}{U_{\max }-U_{c r i}}
$$

$P_{p v \max }$ is the peak power of the PV installation. The enforced standards [15] require that the upper voltage limit $U_{\max }$ equals $110 \%$ of the nominal voltage or $253 \mathrm{~V} . U_{c r i}$ is chosen as $105 \%$ of the nominal voltage or $241.5 \mathrm{~V}$. Figure 2 illustrates that APC is in fact a proportional feedback controller. Here, $I_{P V}$ and $U_{P V}$ are respectively the current and the voltage from the photovoltaic array.

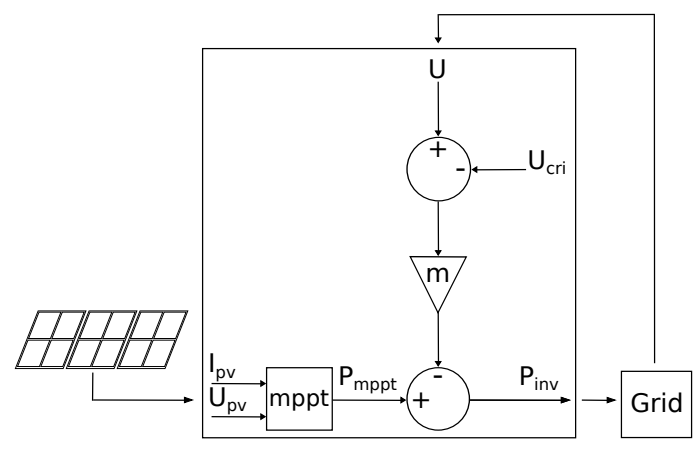

Fig. 2: APC as a proportional feedback controller

\section{BEHAVIOR OF APC ON THE EUROPEAN GRID}

The behavior of the distribution grid has been checked for four scenarios for a 24 hours timeframe. The simulation is static with a discrete time step of one second. In three of the scenarios the penetration level, which is given by Equation 7, is $5 \%$. Here, $\sum_{i=1}^{N} P_{D G}^{i}$ is the power injected by the PV systems, with $\mathrm{N}$ the number of installations, The number in the denominator represents the power of the distribution transformer.

$$
\text { Penetration level [\%] }=\frac{\sum_{i=1}^{N} P_{D G}^{i}}{630 k V A} \times 100
$$

In the first scenario the generators are randomly distributed among the nodes. The second scenario is characterized by a symmetrical distribution of the generators while the third scenario is a worst case scenario in terms of symmetry. In a forth scenario a PV installation is connected to every node. From now on the scenarios are called respectively the Random, Symmetrical, Worst case and Photovoltaic scenario.

The first three columns of Table I give the total energy generation in the different scenarios with and without overvoltage protection (OVP) and APC. A detailed exposition of the individual inverter productions can be found in [16]. Only in the Photovoltaic scenario APC can achieve a small increase $(+0.13 \%)$ in production. In average, the production in case of APC is reduced by $8.5 \%$ in comparison to OVP with a maximum decrease of $13.1 \%$ in the Random scenario. 
Figure 3a shows the power profile of a PV inverter in the early afternoon. It displays the photovoltaic power $P_{\text {solar }}$, the power in case overvoltage protection $P_{O V P}$ and the power after curtailment $P_{A P C}$. Figure $3 \mathrm{~b}$ shows the corresponding voltage profile. Just before 13:00h, the high solar irradiation causes the ten-minute average of the voltage to reach $253 \mathrm{~V}$ and the inverter switches off. It is clear that $P_{A P C}$ falls to powers far less than the photovoltaic power which explains the difference in energy yield between the two control types. The inverter staying online does not make up for the nonnegligible power difference. The voltage $U_{A P C}$ remains well bellow the $253 \mathrm{~V}$ limit.

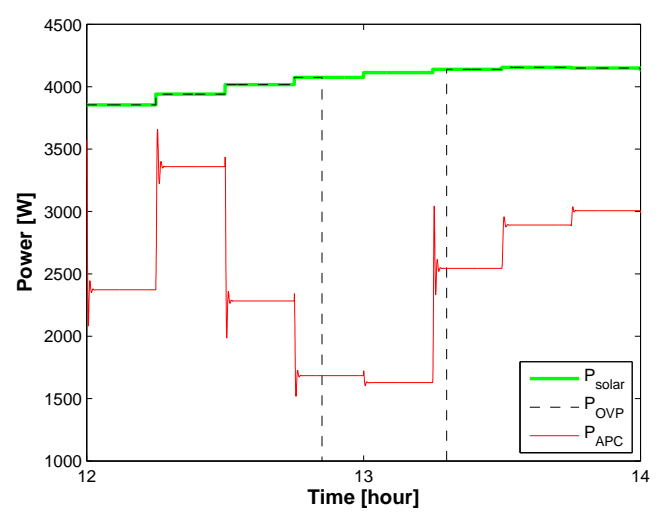

(a) Power profile

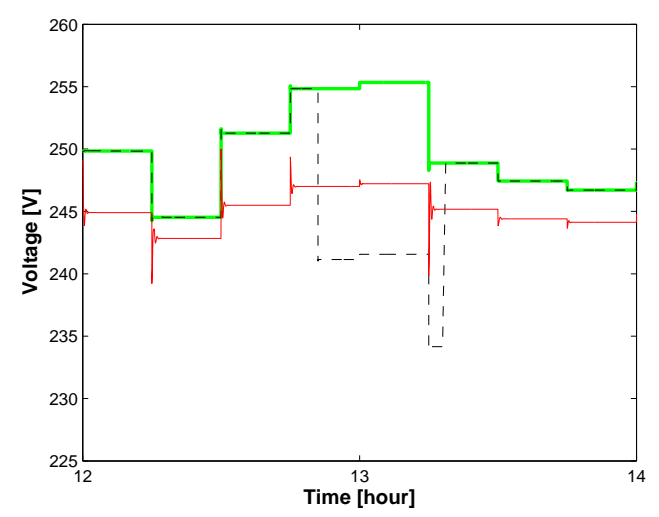

(b) Voltage profile

Fig. 3: Detail of the power and voltage profile in case of APC

\section{Vi. Proportional-Integral Active Power CURTAILMENT}

The discussed method for active power curtailment is in essence a proportional feedback controller. The difference between $U_{c r i}$ and $U_{\max }$ is amplified by means of a proportional gain factor $m$ as defined by Equation 6. The slope factor reduces the injected power in such a way that when the voltages reaches $253 \mathrm{~V}$ the full available power is curtailed. The previous section showed that APC starts the reduction of active power at voltage levels well below the upper voltage limit. By incorporating an integral term, it is possible to start the curtailment at higher voltages. Figure 4 shows the principle of the implemented APC-PI controller. The proposed strategy differs from the one in [17], which is controlled by a multilayer supervision subsystem, because the constrained power is determined by the individual inverters, based on the local voltage. No communication with a central control structure is required.

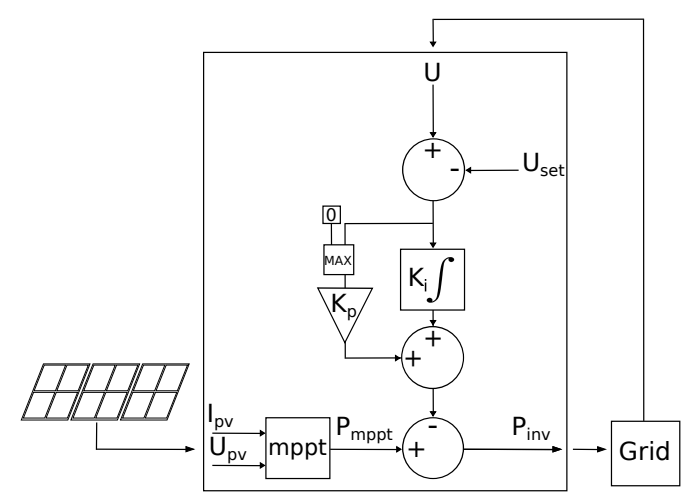

Fig. 4: APC as a PI feedback controller

The controller calculates the difference between the measured local voltage and the setpoint of $250 \mathrm{~V}$. The lower saturation limit of the integrator is set to 0 . This means that the integrator does not undertake action unless the local voltage exceeds the setpoint. This is because the PV installation is limited by the available photovoltaic power and a negative output of the PI controller would mean that the injected power exceeds the available power. It is clear that a negative error will reduce the integrator's accumulated offset in case this is higher than 0 . The proportional action is totally insensitive to negative errors. The upper saturation limit is set to the instantaneous available power by means of a clamping technique. The minimal power after curtailment is indeed limited to $0 \mathrm{~W}$. The controller parameters are obtained from tests to achieve adequate speed and stability.

Figure 5a shows the behavior of the inverter under the same conditions as in figure $3 \mathrm{a}$. Besides $P_{\text {solar }}, P_{O V P}$ and $P_{A P C}$ the figure shows the power profile in case of $P_{A P C-P I}$. The generator injects the fully available power until the local voltage reaches the setpoint of $250 \mathrm{~V}$. From this point on, the controller injects an amount of power that keeps the voltage clamped to the setpoint.

The fourth column of Table I gives the total energy generation in case that the inverters are controlled by APC-PI. A relative production increase of $40 \%$ in comparison to the APC production has been recorded in case of a very asymmetrically loaded feeder. APC-PI has a positive impact on the total energy yield in every scenario with an average relative increase of $22.6 \%$ over the four scenarios.

The main advantage of APC-PI is that it is capable of keeping the voltage within its limits, by sufficiently reducing the power, while starting on high voltage levels. At the same time this results in an important problem. In some cases it has a negative impact on the production of generators located at 


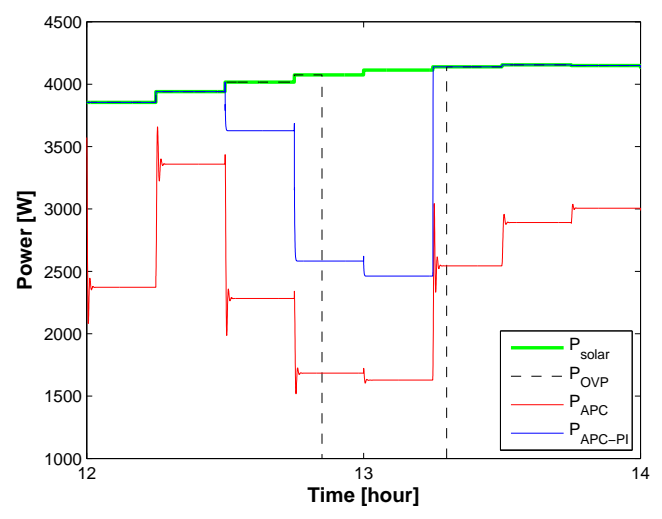

(a) Power profile

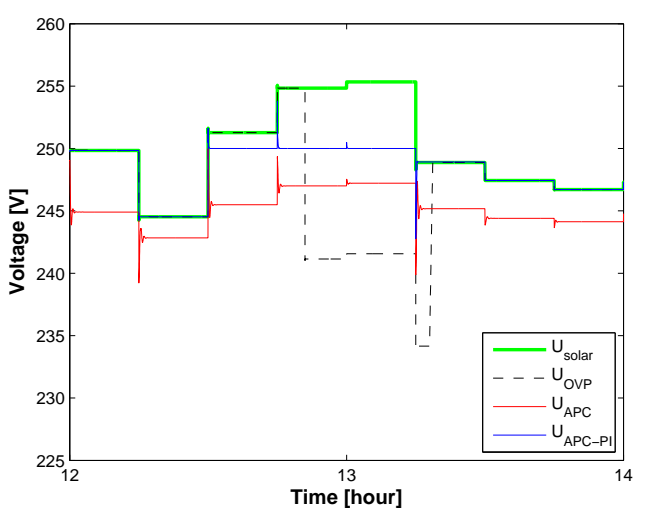

(b) Voltage profile

Fig. 5: Detail of the power and voltage profile in case of APC-PI

\begin{tabular}{|c|c|c|c|c|}
\hline Scenario & no OVP & OVP & APC & APC-PI \\
\hline Random & 222.54 & 212.59 & 184.84 & 218.20 \\
Symmetrical & 222.54 & 206.30 & 185.48 & 211.96 \\
Worst case & 222.54 & 99.06 & 89.10 & 109.89 \\
Photovoltaic & 1543.73 & 1051.55 & 1052.87 & 1424.70 \\
\hline
\end{tabular}

TABLE I: Daily production (in $[\mathrm{kWh}]$ )

the end of the line in comparison to inverter that are controlled by APC. The curtailment of active power in case of APC starts from $241.5 \mathrm{~V}$ onwards. APC-PI only intervenes when the local voltage reaches $250 \mathrm{~V}$. The voltage at nodes at the beginning of the feeder often exceeds $241.5 \mathrm{~V}$ but rarely reaches $250 \mathrm{~V}$. Therefore APC controlled generators inject a reduced amount of active power while inverters operated by APC-PI inject the full photovoltaic power. When all inverters are APC-PI controlled, the inverters at the end of the feeder may face an increased voltage. The voltage at a particular point may rise as high as $249 \mathrm{~V}$ because no controller actively reduces the power as long as the the setpoint of $250 \mathrm{~V}$ is not reached. Even a small injection of power from generators further down the feeder can result in a local overvoltage. As a consequence, producers located at the feeder's end see their yield reduced in favour of the production of their colleagues connected near the transformer. Note that, due to a higher resistance, overand undervoltage are more common further down the line. Figure 6 shows such a situation. The voltage reaches $250 \mathrm{~V}$ at the sixth node of feeder $\mathrm{V}, 425 \mathrm{~m}$ from the transformer, which has a negative impact on the production of generators located further down the line. Due to the displacement of the neutral point the voltage in phase $\mathrm{U}$ and $\mathrm{W}$, indicated by the two remaining graphs, drops.

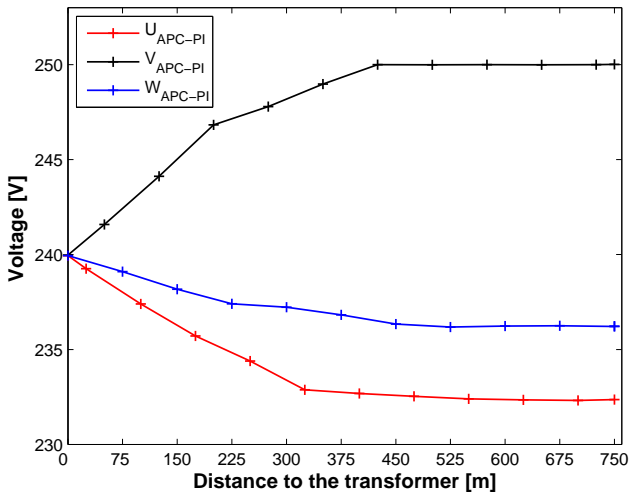

Fig. 6: APC-PI can results in low yields for producers near the feeder's end

\section{CONCLUSION}

The DSO has to cope with the problem of overvoltage due to the injection of photovoltaic power in the distribution network. Tonkoski et al. designed a technique known as Active Power Curtailment to overcome this problem. This method, originally developed for the American split-phase grid, is implemented on two typical European distribution feeders and its behavior has been simulated for four scenarios. PC is indeed capable of limiting the voltage, but at the cost of high energy yield reductions. A modified version of APC with a PI controller limits the voltage and guarantees high overall yields. Because APC-PI controllers do not reduce the power unless the local voltage exceeds the $250 \mathrm{~V}$ threshold, inverters further down the line can face increased voltages. This can result in a negative impact on the production of those generators.

\section{REFERENCES}

[1] A. Pictoel, "VREG marktrapport 11," May 2012

[2] J. Cappelle, J. Vanalme, S. Vispoel, T. Van Maerhem, B. Verhelst, C. Debruyne, and J. Desmet, "Introducing small storage capacity at residential PV installations to prevent overvoltages," in Smart Grid Communications (SmartGridComm), 2011 IEEE International Conference on. IEEE, 2011, p. 5.

[3] C. Debruyne, J. Desmet, J. Vanalme, B. Verhelst, G. Vanalme, and L. Vandevelde, "Maximum power injection acceptance in a residential area," Proceedings ICREPQ. Granada, Spain, 2010.

[4] R. Hledik, "How green is the smart grid?" The Electricity Journal, vol. 22, no. 3, p. 12, 2009.

[5] K. De Brabandere, B. Bolsens, J. Van den Keybus, A. Woyte, J. Driesen, and R. Belmans, "A voltage and frequency droop control method for parallel inverters," Power Electronics, IEEE Transactions on, vol. 22, no. 4, p. 8, 2007. 
[6] R. Tonkoski, L. Lopes, and T. EL-Fouly, "Coordinated active power curtailment of grid connected PV inverters for overvoltage prevention," Sustainable Energy, IEEE Transactions on, p. 1, 2011.

[7] W. Labeeuw and G. Deconinck, "Residential electrical load model based on mixture model clustering and markov models," not published.

[8] A. Wagner, Photovoltaik-Engineering. Springer, 1999.

[9] D. Chan and J. Phang, "Analytical methods for the extraction of solarcell single-and double-diode model parameters from IV characteristics," Electron Devices, IEEE Transactions on, vol. 34, no. 2, p. 7, 1987.

[10] G. Yordanov, O. Midtgård, and T. Saetre, "Two-diode model revisited: Parameters extraction from semi-log plots of iv data," in 25th European Photovoltaic Solar Energy Conference, 2010.

[11] W. Xiao, W. Dunford, and A. Capel, "A novel modeling method for photovoltaic cells," in Power Electronics Specialists Conference, 2004. PESC 04. 2004 IEEE 35th Annual, vol. 3. IEEE, 2004, p. 6.

[12] M. Súri, T. Huld, E. Dunlop, and H. Ossenbrink, "Potential of solar electricity generation in the European Union member states and candidate countries," Solar energy, vol. 81, no. 10, pp. 1295-1305, 2007.

[13] Eandis, "Van productie tot stopcontact," 2010.

[14] H. Pekkala et al., "Challenges in extensive cabling of the rural area networks and protection in mixed networks," Master's thesis, Tampere University of Technology, 2010

[15] Synergrid, "Specifieke technische voorschriften voor decentrale productie-installaties die in parallel werken met het distributienet," 2009.

[16] Y. Vencken, "Wat met een overdosis PV op distributieniveau," MSc thesis, 2012

[17] B. Wang, I. Houssamo, M. Sechilariu, and F. Locment, "A simple PV constrained production control strategy," in Industrial Electronics (ISIE), 2012 IEEE International Symposium on. IEEE, 2012, pp. 969-974. 